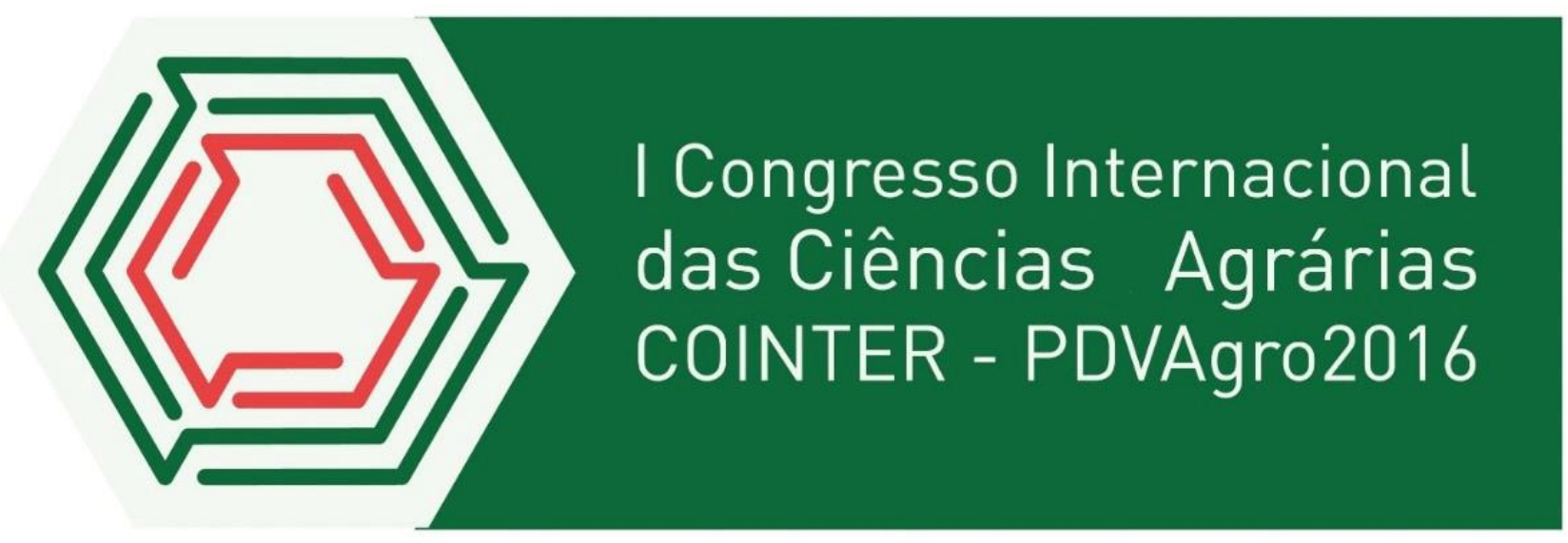

\title{
AVALIAÇÃO FISICO-QUIMICA DO QUEIJO COALHO ARTESANAL E INDUSTRIAL FABRICADO EM SALGUEIRO -PE
}

\author{
Apresentação: Pôster \\ Débora Lívia Marcolino de Souzaㄹ ;ânio Eduardo de Araújo Alves²; Cristiane Ayala de \\ Oliveira $^{3}$
}

\section{Introdução}

O leite está entre os seis primeiros produtos mais importantes da agropecuária brasileira, ficando à frente de produtos tradicionalmente obtidos, como o café beneficiado e o arroz. $\mathrm{O}$ agronegócio do leite e seus derivados, onde o Brasil se posiciona como o sexto produtor mundial, desempenha um papel relevante no suprimento de alimentos e na geração de emprego e renda para a população. De acordo com as informações censitárias, observou-se nos últimos anos o crescimento da produção de leite em todos os Estados da região Nordeste. Essa expansão da produção de leite foi motivada pelas alterações no uso da terra, bem como traduzem o crescimento da produtividade em todos os tipos de estabelecimentos rurais (MENEZES, 2011). Do total de leite produzido no Brasil 33\% é direcionada para a produção de queijo, que sido utilizado ao longo do tempo, como uma forma de preservação do leite. Embora o processo básico de fabricação de queijos seja comum a quase todos, variações na origem do leite, nas técnicas de processamento e no tempo de maturação criam a imensa variedade conhecida (ANDRADE, 2006), em virtude disso, o queijo coalho é alvo de intensas pesquisas. $\mathrm{O}$ que se sabe até o momento, é que os documentos existentes revelam o seu

\footnotetext{
${ }^{1}$ Graduanda do Curso de Tecnologia em Alimentos, IF Sertão- PE - Campus Salgueiro.

${ }^{2}$ Técnico em Agroindústria do Curso de Tecnologia em Alimentos, IF Sertão- PE - Campus Salgueiro.

${ }^{3}$ Profa Doutora, Docente do Curso de Tecnologia em Alimentos, IF Sertão- PE - Campus Salgueiro. E-mail:

cristiane.ayala @ifsertao-pe.edu.br
} 
surgimento em Pernambuco, por volta de 1597. Originalmente produzido nos estados do Nordeste do Brasil a partir de leite cru, o queijo de coalho atualmente vem conquistando espaço e interesse nas outras regiões do Brasil. O queijo de coalho é obtido através da coagulação do leite por meio do coalho ou outras enzimas coagulantes apropriadas, complementada ou não pela ação de bactérias lácteas selecionadas e comercializado em ate dez dias (BRASIL, 2001). Apesar de o queijo Coalho ser um produto muito popular e já fazer parte da cultura gastronômica da região Nordeste, não existe padronização do produto. O objetivo deste trabalho foi avaliar alguns parâmetros físicoquímicos do queijo Coalho artesanal e industrial produzido e comercializado em Salgueiro-PE.

\section{Fundamentação Teórica}

Dentre os produtos de laticínios fabricados no Nordeste, o queijo de coalho é um dos mais difundidos. Este produto possui grande popularidade e é fabricado principalmente nos estados do Rio Grande do Norte, Paraíba, Ceará e Pernambuco há mais de 150 anos (CAVALCANTE; ANDRADE; SILVA; 2004 apud ARAÚJO et al. 2009). É fabricado com massa semicozida e tradicionalmente consumido fresco ou maturado a partir de leite de vaca cru e/ou leite pasteurizado. Antigamente utilizava-se para coagulação do leite o coalho do estômago seco e salgado de animais silvestres ou bezerros (CAVALCANTE, 2007).

No Nordeste do Brasil, a maior parte da produção de queijo-coalho é obtida em pequenas e médias queijarias, as quais movimentam, mensalmente, algo em torno de 10 milhões de reais, o que sinaliza essa atividade como importante para o âmbito social e econômico da região (PERRY, 2004). Apesar de sua importância econômica e grande popularidade, a fabricação de queijo de coalho não conta com tecnologia apropriada para a melhoria de sua qualidade. A falta de critérios de qualidade da matéria prima e das técnicas de processamento permite que produtos de baixa qualidade cheguem ao mercado, tanto do ponto de vista higiênico-sanitário quanto da falta de padronização (NASSU et al., 2001). É necessário que o processo tradicional, geralmente artesanal e a partir de leite cru, acompanhe a evolução das técnicas queijeiras mediante modificações já utilizadas na tecnologia de outros queijos nacionais.

O queijo de coalho é considerado como um patrimônio da população nordestina, desperta o interesse dos agentes promotores do desenvolvimento, dos produtores, de instituições públicas e privadas e gestores públicos (MENEZES, 2011). O conhecimento sobre as características físicoquímicas, como por exemplo, pH, umidade, entre outros, do queijo de coalho é de grande 
importância já que estes influenciam diretamente na qualidade final do queijo (Gomes et al., 2013). Os alimentos podem ser classificados em função do $\mathrm{pH}$ : para alimentos pouco ácidos $(\mathrm{pH}>4,5)$, os ácidos ( $\mathrm{pH} 4$ a 4,5) e os muitos ácidos ( $\mathrm{pH}<4,0$ ) (GAVA et al., 2008). O queijo tem um pH alto (5,7, quando se usa fermento, chegando a 6,5 quando não se usa fermento) criando condições favoráveis para as bactérias contaminantes se desenvolverem, segundo relatado por MUNCK (2004) apud ANDRADE (2006). Segundo Andrade (2006) o queijo de coalho é classificado como um queijo de média a alta umidade, de massa semi-cozida ou cozida, apresentando um teor de gordura no extrato seco entre $35,0 \%$ e $60 \%$

\section{Metodologia}

Foram selecionadas quatro amostras, partindo do princípio que as mesmas deveriam ser produzidas na região do Sertão Pernambucano, sendo duas artesanais, e duas industriais, levando-se em conta os critérios de regularidade de oferta e tradição da marca no mercado, baseados na metodologia de Andrade (2006). As análises físico-químicas foram realizadas em triplicata, no Laboratório de Físico-Química dos Alimentos do Instituto Federal de Educação, Ciência e Tecnologia do Sertão Pernambucano - Campus Salgueiro. A caracterização dos queijos de coalho selecionados foi obtida através de análises de $\mathrm{pH}$, Umidade, Proteína, Gordura, Cinzas e Carboidratos Normas Analíticas do Instituto Adolfo Lutz (IAL, 2008), Acidez titulável e Cloretos (BRASIL, 2006). Os dados obtidos foram submetidos à análise de variância pelo teste $\mathrm{F}$ e, quando significativos, submetidos à comparação entre as médias pelo teste de Tukey a $5 \%$ probabilidade. Sendo analisados por meio do programa estatístico ASSISTAT versão 7.7, 2014 (SILVA, 2014).

\section{Resultados e Discussões}

Os resultados da caracterização físico-química estão destacados na Tabela 1. Observou-se que todos os parâmetros analisados (com exceção do percentual de carboidratos e cloretos) apresentaram resultados com diferença significativa entre os tipos avaliados $(p<0,05)$.

A legislação vigente no Brasil para Queijos é a Instrução Normativa nº 30, de 26 de junho de 2001 (BRASIL, 2001), a qual estabelece que o queijo de coalho é um queijo de média a alta umidade, de massa semi-cozida ou cozida e apresentando um teor de gordura nos sólidos totais variável entre $35,0 \%$ e $60,0 \%$. Os valores de umidade encontrados neste trabalho variaram entre $46,25 \%$ a $48,06 \%$ para o queijo industrial e $48,18 \%$ a $51,05 \%$ e diferiram estatisticamente entre os 
tipos de queijos, apresentando o queijo artesanal valores superiores de umidade, esta, interfere diretamente nas ações metabólicas de microorganismos ao longo da maturação, com suas possíveis consequiências no pH, na textura, no sabor e no aroma. De acordo com os resultados obtidos para teor de umidade, estes podem ser classificados como queijo de "alta umidade", por apresentar valor entre $46,91 \%$ a $60,48 \%$.

Tabela 1: Valores obtidos nas análises físico-quimicas dos queijos coalho comercializados em Salgueiro -PE.

\begin{tabular}{lcccc}
\hline Variáveis & Artesanal 01 & Artesanal 02 & Industrial 01 & Industrial 02 \\
\hline Umidade (\%) & $48,18 \pm 1,41^{\mathrm{b}}$ & $51,05 \pm 0,11^{\mathrm{a}}$ & $46,25 \pm 0,35^{\mathrm{b}}$ & $48,06 \pm 0,08^{\mathrm{b}}$ \\
Cinzas (\%) & $0,73 \pm 0,20^{\mathrm{ab}}$ & $0,92 \pm 0,01^{\mathrm{a}}$ & $0,36 \pm 0,21^{\mathrm{b}}$ & $0,85 \pm 0,13^{\mathrm{a}}$ \\
Proteína (\%) & $9,33 \pm 0,52^{\mathrm{a}}$ & $8,44 \pm 0,88 \mathrm{a}^{\mathrm{b}}$ & $7,69 \pm 0,32^{\mathrm{ab}}$ & $6,87 \pm 0,84^{\mathrm{b}}$ \\
Gordura (\%) & $24,16 \pm 0,28^{\mathrm{a}}$ & $20,83 \pm 1,17^{\mathrm{b}}$ & $26,00 \pm 0,81^{\mathrm{a}}$ & $23,83 \pm 0,23^{\mathrm{a}}$ \\
Carboidratos (\%) & $17,58 \pm 2,23^{\mathrm{a}}$ & $18,73 \pm 1,01^{\mathrm{a}}$ & $19,69 \pm 1,20^{\mathrm{a}}$ & $20,37 \pm 0,74^{\mathrm{a}}$ \\
Cloretos (\%) & $0,71 \pm 0,27^{\mathrm{a}}$ & $0,28 \pm 0,14^{\mathrm{a}}$ & $0,36 \pm 0,27^{\mathrm{a}}$ & $0,18 \pm 0,14^{\mathrm{a}}$ \\
Cloretos em NaCl (\%) & $1,15 \pm 0,45^{\mathrm{a}}$ & $0,46 \pm 0,23^{\mathrm{a}}$ & $0,59 \pm 0,46^{\mathrm{a}}$ & $0,43 \pm 0,15^{\mathrm{a}}$ \\
pH & $6,18 \pm 0,08^{\mathrm{b}}$ & $6,40 \pm 0,02^{\mathrm{a}}$ & $6,31 \pm 0,01^{\mathrm{a}}$ & $6,17 \pm 0,04^{\mathrm{b}}$ \\
Acidez & $0,11 \pm 0,05^{\mathrm{b}}$ & $0,11 \pm 0,08^{\mathrm{b}}$ & $0,24 \pm 0,01^{\mathrm{a}}$ & $0,23 \pm 0,01^{\mathrm{a}}$ \\
\hline
\end{tabular}

a-c: letras diferentes na mesma linha, as médias foram significativas pelo teste de Tukey $(\mathrm{p}<0,05)$ Fonte: Própria.

Com relação aos teores de gordura obtidos, que variaram de $20,83 \%$ a $24,16 \%$ para as amostras artesanais e $23,83 \%$ a 26,00\% para as industriais, o queijo de coalho de acordo com a legislação vigente pode ser definido como semi-gordo (25,0 a 44,9\%), gordo ( 45,0 a 59,9\%) ou extra gordo (mínimo de 60,0\%), as amostras artesanais apresentaram valores abaixo do mínimo estabelecidos pela legislação, já os queijos industriais podem ser classificados na categoria de semigordo. O percentual de cinzas variou de 0,36\%-0,92\% para as amostras a legislação brasileira não estabelece nenhum valor mínimo para o conteúdo de cinzas. Os valores de proteínas encontrados tanto nas amostras industriais como artesanais (Tabela 1) foram inferiores aos reportados por Andrade (2006) que encontrou para as amostras industriais o valor de 22,49\% e para as amostras artesanais encontrou como média 20,70\%. Os valores de pH (Tabela 1) foram superiores aos reportados pela literatura Sousa et al., (2014), ao estudarem o pH do queijo de coalho com e sem inspeção encontraram valores que variaram entre 5,18 - 6,23. O pH é considerado uma determinação importante para caracterizar queijos devido à sua influência na textura, na atividade microbiana e na maturação, já que ocorrem reações químicas que são catalisadas por enzimas provenientes do coalho e da microbiota, que dependem do $\mathrm{pH}$ (Sousa et al.,2014). O valor encontrado para o teor de cloretos em $\mathrm{NaCl}$ variaram entre $0,43 \%$ a $1,15 \%$ nas amostras analisadas. 
O sal contribui com o sabor além de melhorar a textura e a aparência do queijo, controla a fermentação lática determinando o nível ideal de acidez, inibe o desenvolvimento de microrganismos indesejáveis e auxilia na expulsão do soro.

\section{Conclusões}

Com os resultados obtidos foi possível concluir que há uma carência de padronização no processamento do queijo de coalho, levando à necessidade de conhecimento das técnicas empregadas com posterior regulagem das mesmas.

\section{Referências}

ANDRADE, A.A. Estudo do perfil sensorial, físico-químico e aceitação de queijo de coalho produzido no estado do Ceará. 104p. 2006. Dissertação (Mestre em Tecnologia de Alimentos) - Universidade Federal do Ceará, Fortaleza, 2006.

ARAÚJO, M.C.G. de, et al. Análise sensorial e teste de aceitação do queijo de coalho produzido com leite cru e pasteurizado na cidade de Currais Novos. Holos, v. 4, n. 25, p.20-25, 2009. Disponível em: < http://www2.ifrn.edu.br/ojs/index.php/HOLOS/article/viewFile/341/281> Acesso em: 21 de setembro de 2016

BRASIL. Ministério da Agricultura, Pecuária e Abastecimento. Instrução Normativa $\mathrm{n}^{\circ}$ 68, de 12 de dezembro de 2006. Métodos Analíticos Oficiais Físico-Químicos para Controle de Leite e Produtos Lácteos. Diário Oficial da República Federativa do Brasil, Brasília, DF, 14 dez. 2006.

BRASIL. Ministério da Agricultura, Pecuária e Abastecimento. Portaria no 146, de 7 de março de 1996. Regulamento Técnico de Identidade e Qualidade de Queijos. Diário Oficial da República Federativa do Brasil, DF, $11 \quad$ mar. 1996.

BRASIL. Ministério da Agricultura, Pecuária e Abastecimento. Instrução Normativa $n^{\circ} 30$, de 26 de junho de 2001. Anexo II - Regulamento Técnico de Identidade e Qualidade de Queijo de Coalho. Diário Oficial da República Federativa do Brasil. DF, 16 jul. 2001.

CAVAlCANTE, José Fernando Mourão et al . Processamento do queijo coalho regional empregando leite pasteurizado e cultura lática endógena. Ciênc. Tecnol. Aliment., Campinas, v. 27, n. 1, p. 205-214, Mar. 2007 . Available from <http://www.scielo.br/scielo.php?script=sci_arttext\&pid=S010120612007000100036\&lng=en\&nrm=iso>. access on 10 Oct. 2016. http://dx.doi.org/10.1590/S010120612007000100036.

Gava, A. J.; Silva, C. A. B.; Frias, J. R. G. Tecnologia de alimentos: Princípios e aplicações. São Paulo: Nobel, 2008. 511p.

INSTITUTO ADOLFO LUTZ. Normas AnalÃticas do Instituto Adolfo Lutz. Métodos físico-químicos para análises de alimentos. $4^{\mathrm{a}}$ ed. ( $1^{\mathrm{a}}$ Edição digital), 2008. 1020 p.

MENEZES, S. S. M. Queijo de coalho: tradição cultural e estratégia de reprodução social na região 
Nordeste. Revista de Geografia (UFPE), v. 28, n.1, p. 40-56, 2011.

MUNCK, A. V. Queijo de Coalho - Princípios básicos da fabricação (Palestra). Revista do Instituto de Laticínios Cândido Tostes, Juiz de Fora, v. 59, n. 339, p. 13-15, 2004.

NASSU, R.T; ARAÚJO, R. dos SANTOS; BORGES, M.DE FÁTIMA, LIMA, J.R; MACEDO, B.A; LIMA, M.H.P; BASTOS, M. do SOCORRO R. Diagnóstico das condições de processamento de produtos regionais derivados do leite no Estado do Ceará. Fortaleza: Boletim de pesquisa e desenvolvimento Embrapa Agroindústria Tropical, n.1, p.28, 2001.

PERRY, K.S.P. Queijos: aspectos químicos, bioquímicos e microbiológicos. Química. Nova, v.27, p.293$300,2004$.

SILVA, F.A.S. ASSISTAT: Versão 7.7 beta. DEAG-CTRN-UFCG - Atualizado em 01 de abril de 2014. 